\title{
Comparative dose-response study of three anticholinergic agents and fenoterol using a metered dose inhaler in patients with chronic obstructive pulmonary disease
}

\author{
Akihiko Ikeda, Koichi Nishimura, Hiroshi Koyama, Takateru Izumi
}

\begin{abstract}
Background - Inhaled anticholinergics and $\beta$ agonists are widely used in the treatment of patients with chronic obstructive pulmonary disease (COPD). However, dosage requirements have not been thoroughly evaluated and comparative doseresponse data for these agents are limited. Methods - Twenty men with stable COPD of mean (SD) age 69.4 (5.8) years and FEV $0.93(0.38)$ litres were studied in randomised, double blind, crossover, placebo controlled experiments. All of the patients received two, four, eight, and 16 puffs of ipratropium bromide (20 $\mathrm{gg} / \mathrm{puff})$, flutropium bromide ( $30 \mu \mathrm{g} / \mathrm{puff})$, oxitropium bromide $(100 \mu \mathrm{g} / \mathrm{puff})$, fenoterol $(200 \mu \mathrm{g} /$ puff), or placebo in random order on five separate days. Doses were administered by a metered dose inhaler at intervals of 60 minutes to give cumulative doses of two, six, 14, and 30 puffs. Five $\mathrm{mg}$ of nebulised salbutamol was administered 60 minutes after the patient had received the final $\mathbf{1 6}$ puffs of each regimen. Forced expiratory volume in one second $\left(F E V_{1}\right)$, forced vital capacity (FVC), heart rate, and blood pressure were measured five minutes before each treatment and 30 minutes after
\end{abstract} treatment with nebulised salbutamol.

Results - FEV 1 and FVC reached a plateau after administration of a cumulative dose of 14 puffs of ipratropium bromide $(280 \mu \mathrm{g})$ or flutropium bromide $(420 \mu \mathrm{g})$, and after six puffs of oxitropium bromide $(600 \mu \mathrm{g})$. There were no differences with respect to maximum increases in $F E V_{1}$ and FVC amongst the three anticholinergic agents. However, after six puffs oxitropium bromide produced a greater increase in $F_{1}$ than either ipratropium bromide or flutropium bromide. Fenoterol caused a greater increase in both $F_{1}$ and FVC than the three anticholinergic agents after six puffs, as well as a greater increase in pulse rate. Oxitropium bromide produced a greater increase in pulse rate than the other anticholinergics after 14 puffs. The incidence of side effects was dose-related and notable adverse effects were reported after 30 puffs of ipratropium bromide, 14 puffs of oxitropium bromide, and two puffs of fenoterol.

Conclusions - Oxitropium bromide produced a greater bronchodilator effect than either ipratropium bromide or flutropium bromide when used at doses of less than six puffs, without apparent side effects. There were, however, no differences in maximal response between these drugs. Fenoterol may have a greater peak bronchodilator effect than the anticholinergic agents but it causes more adverse effects, even at lower doses. Depending upon the balance between efficacy and side effects, oxitropium bromide may be preferred in the treatment of patients with COPD.

(Thorax 1995;50:62-66)

Keywords: chronic obstructive pulmonary disease, ipratropium bromide, oxitropium bromide, flutropium bromide, fenoterol.

The appropriate use of bronchodilator drugs improves airflow limitation and reduces dyspnoea in patients with chronic obstructive pulmonary disease (COPD). Two classes of inhaled bronchodilators - anticholinergics and $\beta_{2}$ agonists - are available for the management of COPD. Anticholinergic agents show fewer side effects and often greater efficacy in elderly patients. ${ }^{1-6}$ Despite the extensive use of these agents, the dosage requirements for patients with COPD have not been clearly established and most recommended dosages result in less than maximal bronchodilation. ${ }^{7-10}$ Ipratropium bromide and oxitropium bromide are widely used, but few reports compare the effects of these drugs in the treatment of COPD. Flutropium bromide is a quaternary anticholinergic derived from atropine and has a pharmacological profile closely related to that of ipratropium bromide. ${ }^{11}$ Flutropium bromide also possesses some antihistaminic and antiallergic activity ${ }^{12}$ and has been used in Japan for the relief of symptoms of bronchial asthma and COPD. There are, however, few controlled studies either assessing the clinical efficacy of flutropium bromide or comparing it with other anticholinergic agents.

To determine the dosage which produced optimal bronchodilation, a cumulative doseresponse study comparing the currently available anticholinergic agents (ipratropium bromide, flutropium bromide, and oxitropium bromide) and the adrenergic agent fenoterol was undertaken using a metered dose inhaler in patients with stable COPD. 


\section{Methods}

SUBJECTS

Twenty men with stable COPD were recruited from the outpatient clinic at the Chest Disease Research Institute, Kyoto University. All subjects fulfilled the following criteria: (1) a history of more than 20 pack-years of cigarette smoking; (2) a forced expiratory volume in one second $\left(\mathrm{FEV}_{1}\right)$ of $<80 \%$ of the predicted value, and a best post-bronchodilator $\mathrm{FEV}_{\mathrm{l}}$ /forced vital capacity (FVC) ratio of less than 0.7 ; (3) a history of chronic dyspnoea on exertion with or without sputum production and radiological evidence of emphysema; (4) no history suggestive of asthma; (5) no exacerbation of airways obstruction in the preceding three months and no heart disease or any other illness; and (6) no treatment with oral or inhaled corticosteroids in the preceding four weeks, and no current treatment with any oral bronchodilators, including theophylline. No patients were current smokers. The study was approved by the ethics committee of our institute and written informed consent was obtained from each patient.

\section{STUDY DESIGN}

The study was performed in a randomised, double blind, placebo controlled, crossover fashion. Testing was started at approximately the same time each morning on five separate days during a two week period, and the interval between testing ranged from two to four days. The patients received two, four, eight, or 16 puffs of: (1) ipratropium bromide $(20 \mu \mathrm{g} / \mathrm{puff})$; (2) flutropium bromide ( $30 \mu \mathrm{g} / \mathrm{puff})$; (3) oxitropium bromide ( $100 \mu \mathrm{g} / \mathrm{puff})$; (4) fenoterol $(200 \mu \mathrm{g} / \mathrm{puff})$; and (5) placebo in random order. Doses were administered by a metered dose inhaler at one hour intervals to give cumulative doses of two, six, 14, and 30 puffs. Five $\mathrm{mg}$ of nebulised salbutamol in $1 \mathrm{ml}$ saline was administered 60 minutes after the patient had received 16 puffs of each regimen. Spirometric testing was performed initially, 60 minutes after each dose (and just before the administration of the next dose), and 30 minutes after the administration of nebulised salbutamol. Pulse rate and blood pressure were also measured after at least five minutes of rest before each spirometric measurement. Simultaneously, patients were asked to note any side effects such as dryness of the mouth, dysuria, palpitations, or tremor. If the patient developed any intolerable side effects, a pulse rate of more than 120 beats per minute, or a systolic blood pressure of more than $180 \mathrm{~mm} \mathrm{Hg}$ before completing the protocol, the study was stopped. Drinks of coffee were not allowed until the study ended. Inhaled bronchodilators were withdrawn for at least 12 hours before the start of each study day.

Each test trial was performed by the same physician (AI), with the subjects taking one puff from the metered dose inhaler every minute. A spacer device, InspireEase, was used in all trials according to the technique of Newman et al. ${ }^{13}$ The metered dose inhaler with attached spacer was held in the mouth. After the patient had exhaled to functional residual capacity, the canister was activated. Patients then inhaled very slowly until total lung capacity was reached, at which point the breath was held for at least 10 seconds. To ensure that the trials were double blind, identical metered dose inhaler canisters containing either active drug or placebo were prepared in advance, coded, and randomly selected. The treatment codes were not revealed until all 20 patients had completed the protocols.

Spirometric testing was performed according to the methods described in the American Thoracic Society's 1987 update. ${ }^{14}$ Three consecutive flow-volume curves were recorded with a spirometer (AUTOSPIRO AS-600, Minato Medical Science, Osaka, Japan), which was precalibrated with a 3.01 syringe before each day of testing. The highest $\mathrm{FEV}_{1}$ and FVC from the triplicate measurements were analysed and predicted $\mathrm{FEV}_{1}$ and FVC values were calculated according to the 1993 proposal of the Japan Society of Chest Diseases. ${ }^{15}$

Pulmonary function tests were performed within the three months preceding the study and at least 12 hours after the administration of bronchodilators had been suspended. In addition to spirometric testing (CHESTAC$65 \mathrm{~V}$, Chest, Tokyo, Japan) the functional residual capacity was measured by plethysmography (MBR-600, Nihon Kohden, Tokyo, Japan) and this was combined with the inspiratory capacity measured spirometrically to calculate the total lung capacity. The static compliance and airways resistance were also measured by plethysmography. The carbon monoxide diffusing capacity was measured using the single breath technique (CHESTAC$65 \mathrm{~V}$ ).

\section{DATA ANALYSIS}

Friedman's two way analysis of variance was used to compare differences between the five test regimens with respect to $\mathrm{FEV}_{1}$ and FVC (expressed as absolute changes from the baseline), and also with respect to pulse rate and blood pressure (expressed as absolute differences relative to the placebo). When a significant difference existed among groups the Wilcoxon signed rank test was used to identify specifically which differences were significant. Categoric variables were compared using the $\chi^{2}$ test. Data for analyses were expressed as means (SE) and a probability level of less than $5 \%$ (two tailed) was considered significant.

\section{Results}

All 20 patients completed the protocol using the three anticholinergic agents and the placebo. In the trial using fenoterol, however, four patients withdrew after a cumulative dose of 14 puffs and eight patients after 30 puffs because of severe tremor and palpitations. Statistical comparisons between the effects of fenoterol and the anticholinergics were therefore carried out only at doses of two and six puffs.

Baseline clinical data are shown in table 1 . The average patient was elderly with relatively 
Table 1 Clinical data for the 20 patients

\begin{tabular}{|c|c|c|}
\hline & Mean (SD) & Range \\
\hline 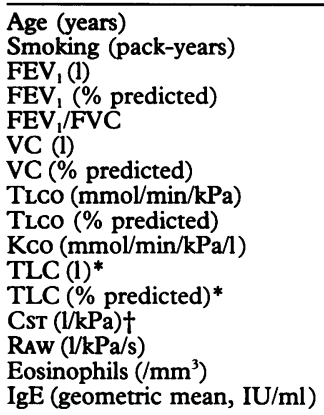 & $\begin{array}{c}69 \cdot 4(5 \cdot 8) \\
69 \cdot 4(36 \cdot 7) \\
0 \cdot 93(0 \cdot 38) \\
37 \cdot 5(15 \cdot 1) \\
39 \cdot 6(6 \cdot 9) \\
2 \cdot 68(0 \cdot 63) \\
79 \cdot 3(16 \cdot 6) \\
5 \cdot 86(1 \cdot 77) \\
74 \cdot 2(20 \cdot 5) \\
1 \cdot 21(0 \cdot 34) \\
8 \cdot 24(1 \cdot 33) \\
146 \cdot 3(25 \cdot 0) \\
4 \cdot 01(2 \cdot 86) \\
0 \cdot 66(0 \cdot 19) \\
151(87) \\
81 \cdot 3\end{array}$ & $\begin{array}{c}56-78 \\
24-165 \\
0 \cdot 43-1 \cdot 89 \\
17 \cdot 4-71 \cdot 9 \\
28 \cdot 4-52 \cdot 0 \\
1 \cdot 55-4 \cdot 26 \\
47 \cdot 7-119 \cdot 3 \\
3 \cdot 41-10 \cdot 08 \\
47 \cdot 5-117 \cdot 8 \\
0 \cdot 82-1 \cdot 89 \\
6 \cdot 29-11 \cdot 39 \\
107 \cdot 3-206 \cdot 7 \\
1 \cdot 22-12 \cdot 24 \\
0 \cdot 43-1 \cdot 03 \\
30-389 \\
(24-282) \ddagger\end{array}$ \\
\hline
\end{tabular}

$\mathrm{FEV}_{1}=$ forced expiratory volume in one second; $\mathrm{FVC}=$ forced vital capacity; $\mathrm{VC}=$ vital capacity; TLCO = carbon monoxide transfer factor; $\mathrm{KcO}=$ carbon monoxide transfer coefficient; TLC = total lung capacity; CST = static compliance; RAW = airway resistance.

* Not measured in two patients because of severe airflow limitation.

tNot measured in three patients because of severe airflow limitation.

$\ddagger$ Normal range.

severe airflow limitation. The baseline values for $\mathrm{FEV}_{1}$ and FVC with the three anticholinergics and the placebo are shown in table 2. With fenoterol the mean (SE) values were $0.94(0.09) 1$ and $2.00(0.15) 1$, respectively. No differences were noted between the five study groups. The mean increases in $\mathrm{FEV}_{1}$ and FVC from baseline are shown in figs 1 and 2 . These two values were greater in the four active treatment groups than the placebo group at all doses and after nebulised salbutamol ( $p<0.01)$.

$\mathrm{FEV}_{1}$ and FVC increased significantly up to a cumulative dose of $280 \mu \mathrm{g}$ (14 puffs) for ipratropium bromide, $420 \mu \mathrm{g}$ (14 puffs) for flutropium bromide, and $600 \mu \mathrm{g}$ (six puffs) for oxitropium bromide. Subsequent doses or nebulised salbutamol had no effect in any group. Fenoterol produced a significant increase in $\mathrm{FEV}_{1}$ and FVC up to a dose of $1200 \mu \mathrm{g}$ (six puffs).

The responses to oxitropium bromide for $\mathrm{FEV}_{1}$ were significantly greater than the responses to ipratropium bromide or flutropium bromide up to a dose of six puffs $(p<0 \cdot 05)$. No significant differences were noted between the responses to ipratropium bromide and flutropium bromide. There were no significant differences among the responses for FVC to the three anticholinergics at any cumulative dose. Fenoterol caused a greater increase in $\mathrm{FEV}_{1}$ and FVC than the three anticholinergics after six puffs $(p<0 \cdot 05)$. It also caused a greater increase in $\mathrm{FEV}_{1}$ following two puffs than ipratropium bromide or flutropium bromide. There were no significant differences in the

Table 2 Mean (SE) baseline values and maximal increases in FEV and FVC (l) after the administration of three anticholinergics and placebo

\begin{tabular}{|c|c|c|c|c|c|}
\hline & Placebo & Ipratropium & Flutropium & Oxitropium & $p$ \\
\hline $\begin{array}{l}\mathrm{FEV}_{1}(\mathrm{l}) \\
\text { Baseline } \\
\text { Maximum }\end{array}$ & $\begin{array}{l}0.93(0.08) \\
0.06(0.02)\end{array}$ & $\begin{array}{l}0.89(0.08) \\
0.24(0.04)\end{array}$ & $\begin{array}{l}0.87(0.08) \\
0.23(0.03)\end{array}$ & $\begin{array}{l}0.91(0.08) \\
0.26(0.04)\end{array}$ & $\begin{array}{l}\text { NS* } \\
\text { NSt }\end{array}$ \\
\hline $\begin{array}{l}\text { FVC (1) } \\
\text { Baseline } \\
\text { Maximum }\end{array}$ & $\begin{array}{l}1.99(0.13) \\
0.14(0.04)\end{array}$ & $\begin{array}{l}1.87(0.13) \\
0.54(0.07)\end{array}$ & $\begin{array}{l}1.87(0.13) \\
0.50(0.07)\end{array}$ & $\begin{array}{l}1.91(0.14) \\
0.47(0.07)\end{array}$ & $\begin{array}{l}\text { NS* } \\
\text { NSt }\end{array}$ \\
\hline
\end{tabular}

* No significant differences among the three anticholinergics and placebo.

+ No significant differences among the three anticholinergics.

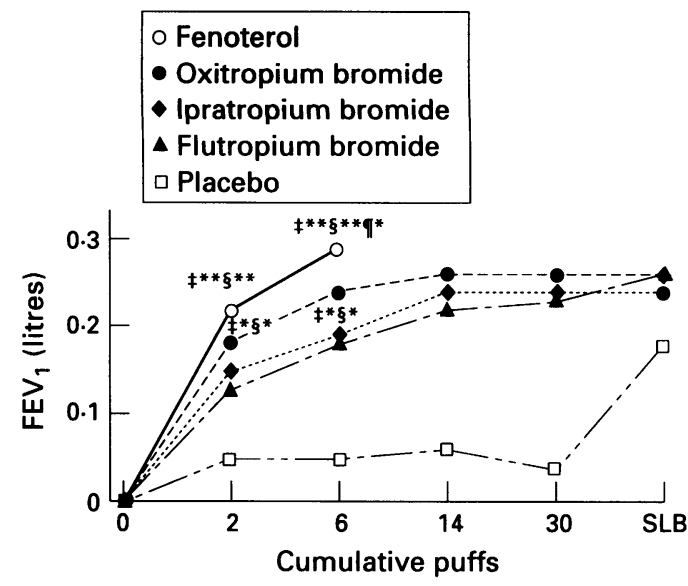

Figure 1 Changes in FEV . Following treatment with active drugs $F E V$, values in all groups were significantly greater than in the placebo group for all measurements $(p<0.01)$. $¥$ Significantly different from flutropium bromide, ifrom ipratropium bromide, Ifrom oxitropium bromide. ${ }^{*} p<0.05,{ }^{* *} p<0.01$.

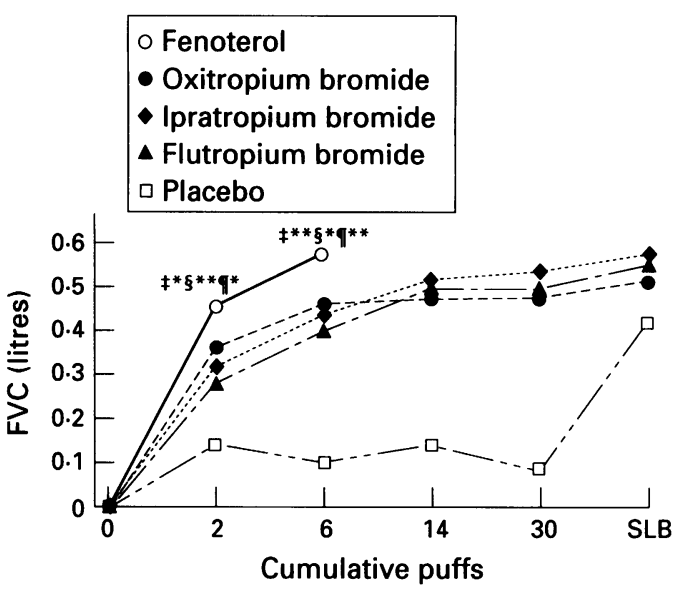

Figure 2 Changes in FVC. Following treatment with active drugs FVC values in all groups were significantly greater than in the placebo group for all measurements $(p<0 \cdot 01)$. $¥$ Significantly different from flutropium bromide, Ifrom ipratropium bromide, Ifrom oxitropium bromide. ${ }^{*} p<0.05, * * p<0.01$.

maximum increases in $\mathrm{FEV}_{1}$ or FVC induced by the three anticholinergics (table 2 ).

The mean changes in pulse rate relative to the values recorded for the placebo group are shown in fig 3. Fenoterol caused a significant dose-related increase in pulse rate, greater then the anticholinergic agents up to a dose of six puffs. Oxitropium bromide also caused a significant dose-related increase in pulse rate which was greater than the other anticholinergics after 14 puffs or more. No significant changes were recorded after treatment with ipratropium bromide or flutropium bromide. There were no significant differences among the four treatment groups in blood pressure changes when compared with the placebo group.

Oxitropium bromide caused a greater increase in the incidence of oral dryness after 14 puffs, and of dysuria after 30 puffs, than the other drugs $(p<0.05)$. Ipratropium bromide caused a greater increase in the incidence of oral dryness after 30 puffs than placebo $(p<0.05)$. Flutropium bromide did not cause significantly more side effects than placebo. Fenoterol 


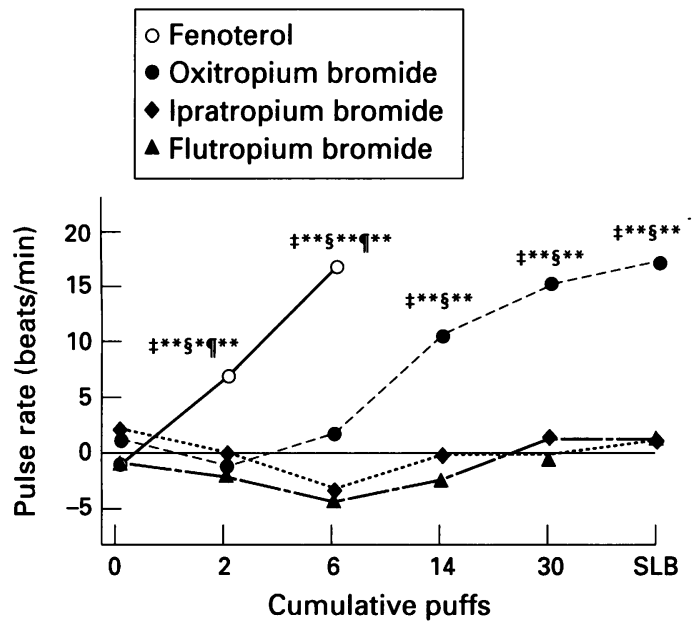

Figure 3 Changes in pulse rate. Mean values of differences between the drug and placebo groups are shown. $¥$ Significantly different from flutropium bromide, \from ipratropium bromide, Ifrom oxitropium bromide. ${ }^{*} p<0.05$, $* * p<0.01$.

caused a greater increase in the incidence of tremor at each dose, and of palpitations at doses of more than six puffs, than any of the other drugs $(p<0.05)$ (table 3$)$.

\section{Discussion}

The present study has shown that the dose needed to produce near maximal bronchodilation was seven times higher than that recommended for both ipratropium bromide and flutropium bromide, and three times that for oxitropium bromide. This result is even more significant considering that the drugs had equal efficacy. Very few studies have attempted to determine the optimal dose of bronchodilators in patients with COPD, although evidence suggests that therapeutic dosages of ipratropium bromide or oxitropium bromide may be suboptimal in COPD. ${ }^{27810}$ Since penetration of inhaled particles into the airways is impaired when the airways are obstructed, higher than recommended dosages of bronchodilators may be needed for a maximal effect in patients with severe airways obstruction. ${ }^{1617}$

In previous studies in which bronchodilator effects have been assessed using a metered dose inhaler with the InspirEase spacer in patients with COPD, the peak effect of ipratropium

Table 3 Reported side effects. Values are expressed as a cumulative percentage of patients experiencing each effect

\begin{tabular}{|c|c|c|c|c|}
\hline & \multicolumn{4}{|c|}{ Cumulative puffs } \\
\hline & 2 & 6 & 14 & 30 \\
\hline $\begin{array}{l}\text { Oral dryness } \\
\text { Ipratropium } \\
\text { Flutropium } \\
\text { Oxitropium }\end{array}$ & & 5 & $\stackrel{5}{40 \dagger}$ & $\begin{array}{l}20^{*} \\
10 \\
65 \dagger\end{array}$ \\
\hline $\begin{array}{l}\text { Dysuria } \\
\text { Oxitropium }\end{array}$ & & & & $30 \dagger$ \\
\hline $\begin{array}{l}\text { Palpitation } \\
\text { Fenoterol }\end{array}$ & 5 & $20+$ & $45 t$ & $60 \dagger$ \\
\hline $\begin{array}{l}\text { Tremor } \\
\text { Fenoterol }\end{array}$ & $25 \dagger$ & $60 t$ & $90 \dagger$ & $100 \dagger$ \\
\hline
\end{tabular}

* Significantly higher than fenoterol and placebo.

† Significantly higher than other regimens. bromide, oxitropium bromide, or fenoterol was reached approximately 60 minutes after inhalation. ${ }^{1819}$ Flutropium bromide has a pharmacological profile closely related to that of ipratropium bromide ${ }^{11}$ and similarities between the two agents with respect to peak bronchodilator responses and side effects have been demonstrated. $^{20}$ The spirometric measurements were therefore made one hour after the administration of each dose. A conventional dose $(200 \mu \mathrm{g})$ of oxitropium bromide may have bronchodilation effects equal to twice that of ipratropium bromide $(80 \mu \mathrm{g})$ in the treatment of asthma. ${ }^{21}$ There are, however, no previous studies in which the equivalence of the conventional doses of ipratropium bromide $(40 \mu \mathrm{g})$, flutropium bromide $(60 \mu \mathrm{g})$, and oxitropium bromide $(200 \mu \mathrm{g})$ have been assessed in the treatment of COPD. The doses we used per puff are therefore the standard doses currently recommended in the marketing of these agents.

Six puffs of oxitropium bromide $(600 \mu \mathrm{g})$ could achieve near maximal bronchodilation, while the other drugs needed 14 puffs $(280 \mu \mathrm{g}$ for ipratropium bromide and $420 \mu \mathrm{g}$ for flutropium bromide). Since maximal bronchodilating effects were similar for these drugs, oxitropium bromide is apparently pharmacologically less potent. The strength of each puff, however, may differ between oxitropium bromide and the other two drugs. Oxitropium bromide produced greater effects at doses of less than six puffs which are typically used in clinical practice. Differences in the increase in $\mathrm{FEV}_{1}$ by the three drugs at these doses were small. While a small improvement in airflow may be of benefit to patients with relatively severe COPD, the present study does not address the possibility that oxitropium bromide might provide improved symptom relief over the other two drugs. However, since fewer puffs of oxitropium bromide may be required to produce a maximal increase in $\mathrm{FEV}_{1}$, better patient compliance might be expected.

Fenoterol produced a greater peak response than either ipratropium bromide or oxitropium bromide when used in lower doses, but it also caused more side effects. The dose per actuation of fenoterol in the present study was twice that normally recommended to produce these effects. The reasons for choosing such a high dose were twofold: (1) when using a metered dose inhaler a $100 \mu \mathrm{g}$ per puff dose of fenoterol was not available; (2) some studies in which the effects of fenoterol have been compared with those of the other anticholinergics have suggested that $400 \mu \mathrm{g}$ fenoterol would approximate a dose equivalent to $40 \mu \mathrm{g}$ ipratropium bromide or $200 \mu \mathrm{g}$ oxitropium bromide. ${ }^{1922}$ Fenoterol is at least equal to, and may be superior to, the anticholinergics. ${ }^{116192223}$ Other studies comparing the effects of anticholinergics and $\beta$ agonists other than fenoterol have shown the opposite. ${ }^{2-6}$ It has been suggested that, whilst the function of $\beta_{2}$ receptors may become impaired with age, ${ }^{24}$ their responsiveness is nonetheless well preserved and a steep doseresponse relationship with $\beta_{2}$ agonists persists. ${ }^{25}$ 
Since fenoterol is currently marketed at a higher dose per puff than other $\beta$ agonists, ${ }^{26}$ it might be expected to produce greater benefits, but it may also cause more side effects and can hardly be recommended as the drug of choice in the treatment of COPD.

In conclusion, oxitropium bromide produced significantly greater bronchodilator effects than either ipratropium bromide or flutropium bromide when used in doses of less than six puffs, without apparent side effects. Although maximal bronchodilator effects were similar for all three anticholinergics, oxitropium bromide may be the most useful drug in clinical practice for the treatment of patients with COPD.

This study was supported in part by a research grant from the Smoking Research Foundation of Japan. The authors are grateful to Dr Naoharu Sugiura for the measurements that required body plethysmography, and to Nippon Boehringer Ingelheim for providing the test drugs.

1 Hughs JA, Tobin MJ, Bellamy D, Hutchinson DCS. Effects of ipratropium bromide and fenoterol aerosols in pulmonary emphysema. Thorax 1982;37:667-70.

2 Easton PA, Jadue C, Dhingra S, Anthonisen NR. A comparison of the bronchodilating effects of a beta-2 adrenergic agent (albuterol) and an anticholinergic agent (ipratopium bromide), given by aerosol alone or in (ipratopium bromide), given by aeroso
sequence. $N$ Engl $\mathcal{M}$ Med 1986;315:735-9.

3 Poppius H, Salorinne Y. Comparative trial of a new anticholinergic bronchodilator Sch 1000 , and salbutamol in chronic bronchitis. BMf 1973;4:134-6.

4 Baigelman W, Chodosh S. Bronchodilator action of the anticholinergic drug, ipratropium bromide (Sch 1000), as an aerosol in chronic bronchitis and asthma. Chest 1977 71:324-8.

5 Tashkin DP, Ashutosh K, Bleecker ER, Brit EJ, Cugell DW, et al. Comparison of the anticholinergic bronchodilator ipratropium bromide with metaproterenol in chronic obipratropium bromide with metaproterenol in chronic ob-
structive pulmonary disease. A 90 day multi-center study. structive pulmonary disease. A 90 day

6 Braun SR, Mckenzie WN, Copeland C, Knight L, Ellersieck $M$. A comparison of the effect of ipratropium and albuterol in the treatment of chronic obstructive airways disease. Arch Intern Med 1989;149:544-7.

7 Allen CJ, Campbell AH. Dose-response of ipratropium bromide assessed by two methods. Thorax 1979;34:137-9.

8 Peel ET, Anderson G. A dose response study of oxitropium bromide in chronic bronchitis. Thorax 1984;39:453-6.

9 Vathenen AS, Britton JR, Ebden P, Cookson JB, Wharrad
HJ, Tattersfield AE. High-dose inhaled albuterol in severe chronic airflow limitation. Am Rev Respir Dis 1988;138: 850-5.

10 Gross NJ, Bankwala Z. Effects of an anticholinergic bronchodilator on arterial blood gases of hypoxemic patients with chronic obstructive pulmonary disease. Am Rev Respir Dis 1987;136:1091-4.

11 Banholzer R, Pook K-H, Stiasni M. Synthesis of the bronchospasmolytic agent flutropium bromide and some of homologous and configuration isometric compounds. Arzhomologous and configuration isom

12 Yanaura S, Mizuno H, Goto K, Kamei J, Hosokawa T, Ohtani K, et al. Effects of 8-(2-fluoroethyl)-3 $\alpha$-hydroxy$1 \alpha \mathrm{H}, 5 \alpha \mathrm{H}$-tropaniumbromide benzilate $(\mathrm{Ba} 598 \mathrm{Br})$ on allergy- and drug-induced asthmatics. fapan $\mathcal{F}$ Pharmacol 1983;33:971-82.

13 Newman SP, Woodman G, Clarke SW, Sackner MA. Effect of InspireEase on the deposition of metered-dose aerosols in the human respiratory tract. Chest 1986;89:551-6.

14 Medical Section of the American Lung Association. Standardization of spirometry - 1987 update. Am Rev Respir Dis $1987 ; 136: 1285-98$.

15 Physiological Section of the Japan Society of Chest Diseases. fFTD 1993;31:Appendix. [Japanese]

16 Dolovich MB, Sanchis J, Rossman C, Newhouse MT. Aerosol penetrance: a sensitive index of peripheral airways obstruction. $\mathcal{F}$ Appl Physiol 1976;40:468-71.

17 Pavia D, Thomson ML, Clarke SW, Shannon HS. Effect of lung function and mode of inhalation on penetrance of aerosol in to the human lung. Thorax 1977;32:194-7.

18 Ledoux EJ, Morris JF, Temple WP, Duncan C. Standard and double dose ipratropium bromide and combined ipratropium bromide and inhaled metaproterenol in COPD. Chest 1989;95:1013-6.

19 Koyama H, Nishimura K, Ikeda A, Izumi T. A comparison of the bronchidilating effects of oxitropium bromide and fenoterol in patients with chronic obstructive pulmonary disease. Chest 1993;104:1743-7.

20 Bauer R, Fugner A. Pharmacology of the anticholinergic bronchospasmolytic agent flutropium bromide. Arzneimittelforschung 1986;36:1348-52.

21 Peel ET, Anderson G, Cheong B, Broderick N. A comparison of oxitropium bromide and ipratropium bromide parison of oxitropium bromide and ipratrop

22 Nolte D. Double-blind crossover comparison between a $\beta$-adrenergic agent and a new anticholinergic agent by metered-dose inhaler. Respiration 1978;36:98-104.

23 Wesseling G, Mostert R, Wouters FM. A comparison of the effects of anticholinergic and $\beta_{2}$-agonist and combination therapy on respiratory impedance in COPD. Chest 1992; 101:166-73.

24 van Schayck CP, Folgering $H$, Harbers $H$, Maas $K L$, van Weel C. Effects of allergy and age on responders to
salbutamol and ipratropium bromide in moderate asthma salbutamol and ipratropium bromide in modera
and chronic bronchitis. Thorax 1991;46:355-9.

25 Lipworth BJ, Clark RA, Dhillon DP, McDevitt DG. Comparison of $\beta$-adrenoceptor responsiveness following prolonged treatment with low and high doses of inhaled terbutaline in chronic obstructive pulmonary disease. $\mathrm{Am}$ Rev Respir Dis 1990;142:338-42.

26 Wong CS, Pavord ID, Williams J, Britten JR, Tattersfield AE. Bronchodilator, cardiovascular, and hypokalaemic effects of fenoterol, salbutamol, and terbutaline in asthma. effects of fenoterol, salbutam 